\title{
Volunteerism During Young Adulthood: An Italian Investigation into Motivational Patterns
}

\author{
Elena Marta • Chiara Guglielmetti · Maura Pozzi
}

Published online: 28 September 2006

(C) International Society for Third-Sector Research and The Johns Hopkins University 2006

\begin{abstract}
This paper explores the motivational frame of Italian young adults involved in volunteerism and its relation to several variables included in Omoto and Snyder's Volunteer Process Model framework. Some 461 Italian young adults (aged 24-31) involved in voluntary activities with children and adolescents were considered. Referring to Omoto and Snyder's functionalist and motivational framework, a Ward's method cluster analysis was performed to identify specific patterns of motivations originating from the aggregation of 4 factors of motivation (social, career, ego-protective, and values) measured with the Voluntary Function Inventory (VFI). The results show that young volunteers are inspired by a distinctive and composite pattern of motivations, including both self and other-oriented motivations. Multiple motivations underlying the activities are associated to satisfaction and good integration in the organization confirming that people spurred by more than one motivation are less vulnerable to costs related to the activity and are more likely to maintain a longer involvement.
\end{abstract}

Keywords Young adulthood $\cdot$ Volunteerism $\cdot$ Motivations $\cdot$ Italy

\section{Introduction}

It is surprising that very little is known about youth volunteering, the psychological and social characteristics of this population segment in terms of motivations for and effects of volunteering and the organizational context in which the voluntary action takes place. Research on volunteerism is primarily based on adult and elderly volunteers. As Kirkpatrick Johnson, Beebe, Mortimer, and Snyder (1998) argue, the results of research into these phases

\footnotetext{
E. Marta $\cdot$ M. Pozzi $(\bowtie)$

Psychology Department, Catholic University of Milano, L.go Frà A. Gemelli 1, 20123 Milano, Italy

e-mail: maura.pozzi@unicatt.it

C. Guglielmetti

Statal University of Milano, Milano, Italy
} 
of the life cycle cannot automatically be applied to other generations since the motivations and the effects of voluntary action are different for each generation.

What do specific studies on young adult volunteers teach us about volunteerism during young adulthood? In particular, which are the motivations that move young adults to engage in these activities? In truth, "we know little about the factors that draw young people into volunteerism" (Oesterle, Kirkpatrick Johnson, \& Mortimer, 2004, p. 1124).

These considerations reveal how important it is to conduct in-depth research on volunteerism specifically during the period of young adulthood. Referring to Omoto and Snyder's Volunteer Process Model (1995) as a theoretical framework, this paper's aim is, first, to identify subgroups of Italian young adult volunteers who share similar patterns of scores on a set of motivations to commit in their activity and, second, to examine how the subgroups were associated with some variables considered crucial when studying volunteerism (i.e., pro-social personality, satisfaction with the organization and the activity, integration with the organization, length and intention to maintain the commitment) and demographics.

In this research we consider volunteerism as a specific type of sustained, planned, prosocial behavior that benefits strangers and occurs within an organizational setting, as defined by Clary and colleagues (Clary et al., 1998; Omoto \& Snyder, 1995; Penner, 2002; Snyder \& Omoto, 2000; Wilson, 2000). In the following section we review several studies on motivations and their role in voluntary actions and on volunteerism in young adulthood.

\section{The theoretical approach: Volunteer process model}

Based on the functionalist theory by Katz (1960) and by Smith, Bruner, and White (1956), Omoto and Snyder suggested that volunteerism serves different functions for different people. These functions are translated into motivations to volunteer. Omoto and Snyder (1995) introduce motivations in the antecedent stage of their model, the Volunteer Process Model (VPM). This model develops along three stages in volunteerism: antecedents, experiences, and consequences of volunteering. Furthermore, it includes three different levels: individual, organizational, and societal. In their theoretical framework, Omoto and Snyder correlate these three levels with the three stages of the volunteer's service.

The antecedent stage regards the individual, organizational, and societal features that exist prior to a person becoming a volunteer (i.e., pro-social personality and motivations to volunteer). The experience stage regards the daily contacts between the volunteer and his/her organization (i.e., satisfaction with the activity and the organization, and integration with the latter) whereas the outcomes concern the results of the interaction of the first two stages (i.e., the length of service). In accordance with Grube and Piliavin (2000), the intention to continue to volunteer could also be considered as an outcome variable. At the antecedents stage different dispositional factors are likely to be important, first of all motivations.

Studies on motivations to volunteer using Omoto and Snyder's (1995) approach have found that they can be classified into six distinct factors for engaging in volunteer service (Clary et al., 1998; Omoto \& Snyder, 1995). These we discuss in turn. The values motivation concerns volunteerism as an opportunity for individuals to express altruistic or humanitarian values and attitudes. It allows us to distinguish between volunteers and non-volunteers. Chacon and Vecina (2000) also found that, in the area of providing assistance to the victims of AIDS, volunteers identified this motivation as the most important. This was especially true of those who had been involved in volunteerism for the most time. A second motive is the social motivation, which has to do with relationships with others. Volunteerism may offer opportunities to be with one's friends or to engage in an activity viewed favorably 
by important others. This motivation is prominent in studies about blood donation, where initial donors declare that an important reason for their action is social pressure (Piliavin, forthcoming).

The understanding motivation involves the opportunity for volunteers to embrace new learning experiences and the possibility of exercising knowledge, abilities, and skills that might otherwise go unused. For example, Gidron's (1977) study about volunteerism in mental health institutions found that some volunteers had a strong desire to learn from their participation in their volunteer activity. The career motivation is concerned with careerrelated benefits that might be obtained by participating in volunteer work. This function is satisfied when people volunteer to learn skills not only for the sake of learning but in order to explore job opportunities or to meet potential career contacts. The importance of this motivation is demonstrated in Jenner's (1982) study of Junior League Volunteers, many of who volunteered to prepare for a new job or to achieve career-relevant skills.

The ego-protective motivation is related to the functioning of the Ego. This motivation centers on protecting the Ego from negative features of the self and, through helping behaviors, may serve to reduce guilt over being more fortunate than others. Evidence of this function is found in Keniston's (1971) sample of student activists who became involved out of a sense of "existential guilt" (Hoffman, 1976) or feelings of culpability for the plight of the less advantaged and in Frisch and Gerrard's (1981) study of Red Cross volunteers, some of whom volunteered to escape negative sensations. The last motivation, self-enhancement, suggests that individuals may engage in volunteer service for Ego's growth and development and involves the Ego's strivings. It is related to obtaining satisfaction through personal growth, such as improving self-esteem or self-image (Jenner, 1982). Studies about volunteers in mental hospitals highlighted an increased self-acceptance as a result of volunteering (King, Walder, \& Pavey, 1970).

In addition, in previous studies (1995), Omoto and Snyder also conceptualized a more community-based motivation, the so-called community concern. This latter motivation reflects people's sense of obligation to or concern about a community or social group. These seven factors can be further reduced into two basic types of motivations: self-focused and other-focused motivations, which are qualitatively distinct. The values and the community concern motivations are other-oriented in nature and reflect how volunteer work can benefit other people, while understanding, social, career, ego-protective, and self-enhancement motivations are self-focused in nature and center around personal gains that can be obtained through voluntary service.

Prior research has suggested that self- and other-oriented motivations work in different ways to influence the volunteer life-course (Omoto \& Snyder, 1995; Omoto, Snyder, \& Berghuis, 1993; Penner \& Finkelstein, 1998). Omoto and Snyder (1995) found that selforiented motivations predicted length in volunteer service while other-oriented motivations, such as expression of compassionate values or community concern, did not. Other studies (Deaux \& Stark, 1996; Penner \& Finkelstein, 1998) obtain the opposite result: other-oriented motivations predict length of service. Furthermore, Clary and colleagues (1998) found selffocused motivations are predictive of the intention to remain active in volunteering for a longer duration of time. Other-focused motivations emerged as being related to initiating voluntary service (Okun, 1994; Omoto \& Snyder, 1995). In the opinion of Omoto and Snyder, "the opportunity to have personal self-oriented, and perhaps even selfish functions served by volunteering was what kept volunteers involved" (1995, p. 683). All this suggests that it is important to shift from the single motivation analysis to a more composite approach in which the focus is the specific combination of self and other oriented motivations. 
The recent conceptualization of volunteerism proposed by Kiviniemi, Snyder, and Omoto (2002) highlights the outcomes of combining different motivations in pro-social behavior. These authors assume that "each individual acts in an attempt to satisfy not one but multiple motivations" (Kiviniemi et al., 2002, p. 733), even though engaging in voluntary actions with more than one motivation seems to lead to more negative outcomes, such as stress and reduced satisfaction.

In summary, the literature demonstrates that, if motivations for action (such as volunteering) are seen to reflect psychological needs, than these needs can vary among people or even within a person over time and in different contexts. This implies that the choice to begin and continue voluntary involvement is represented for each individual by a pattern of intertwined and fluid motivations rather than by a single motivation that is idiosyncratic and stable. All of the above demonstrates how important it is to understand the reasons that spur young people to become involved in volunteerism in order to reduce the problems of attrition and burn-out in the volunteer organization, and to discern the variables that are useful to programs that try to attract young people to volunteerism.

\section{The specificity of young-adult volunteerism}

The literature on young volunteers focuses primarily on two issues: (a) the characteristics of volunteers, and especially their personality and motivations, and (b) the potential effects of volunteering, i.e., the analysis of agency, social relatedness and moral-political development, and awareness (Kirkpatrick Johnson et al., 1998; Yates \& Youniss, 1996).

A very fruitful body of research has yielded what has been defined "the personality of the volunteer:" as compared to their peers, young volunteers are characterized by higher levels of self-esteem, optimism, and self-efficacy (Allen \& Rushton, 1983; Hart \& Fegley, 1995; Pancer, Pratt, \& Hunsberger, 1998). Moreover, they have higher work aspirations, better academic results, and greater motivation in their studies (Kirkpatrick Johnson et al., 1998; Fletcher, Elder, \& Mekos, 2000). Young adults involved in voluntary organizations also demonstrate a high propensity towards pro-social attitudes and behaviors, which, moreover, seem to be reinforced by their very involvement in volunteerism.

In regard to specific aspects of young adult volunteerism, a young adult's motivational framework at the beginning of the commitment in voluntary organizations appears to be composite. It has the same strong values- and community-oriented base as an adult's. Moreover, it draws on experiences that lead to the competence and ability necessary for self-growth and entry into the job market (Capanna, Steca, \& Imbimbo, 2002; Omoto, Snyder, \& Martino, 2000; Sundeen \& Raskoff, 1994; Wuthnow, 1995).

In-depth interviews with 12 Italian young volunteers and self-reports filled out by 155 Italian young volunteers showed results consistent with the studies cited above. Young people's initial volunteerism is determined both by self-oriented and other-oriented motivations, but they maintain the commitment for an extended time on the basis of otheroriented motivations (Guglielmetti \& Marta, 2003; Pozzi \& Marta, 2006). More specifically, in a recent study Okun and Schultz (2003) considered the effects of age on Omoto and Snyder's volunteer motivations (1995). The results revealed that as age increases, career and understanding volunteer motivations decrease and the social volunteer motivation increases. Moreover, age did not contribute to the prediction of self-enhancement, ego-protective, and values volunteer motivations.

As for the effects of volunteerism, the studies show that voluntary service is useful for socialization and for getting involved in the social context of belonging (Sundeen \& Raskoff, 
1994). Moreover, doing voluntary work favors political participation (Flanagan, Bowes, Jonsonn, Csapo, \& Sheblanova, 1998; Hanks, 1981), civic commitment, and the support of pro-social norms (Youniss \& Yates, 1997). It also promotes well being (Benson, 1993). Together with these functions, Youniss and Yates highlight how volunteerism favors social generation bonds and the connection between youths and adults and their respective ideologies and social traditions. This connection promotes communication between generations through experiences that are shared by individuals (Kaplan, 1997).

In addition, since volunteerism, in the great majority of cases, takes place within an organizational setting, organizational variables - such as satisfaction and integration in the organization - are far more important than in other forms of helping, such as one-to-one interpersonal kinds of helping (Penner, 2002). Thus, it becomes important to also understand the interplay between motivations and organizational variables in the decision for continuity or discontinuity in the choice to become involved in voluntary action and in the willingness to sustain it (Pozzi \& Marta, 2006).

\section{Research aims and method}

Omoto and Snyder's Volunteer Process Model (Omoto \& Snyder, 1995; Snyder \& Omoto, 2000) is the conceptual model of volunteer behavior that guides this research. Following the above mentioned theoretical framework, the present study has a three-fold aim. First, to discover the different clusters of motivations of young-adults that seek out opportunities to be engaged in voluntary activities. Second, to study the link between these clusters and other crucial variables of Omoto and Snyder's Volunteer Process Model, such as: access to the organization; pro-social personality (antecedent); satisfaction with the organization and the activity of volunteers; integration with the organization (experience); length of commitment; and intention to maintain the commitment in the future (outcomes). And third, to investigate the link between clusters of motivations and socio-demographic variables.

\section{Participants}

There were 461 young-adult volunteer participants, aged 24-31 $(M=26.9$, S.D. $=1.6)$, proportionally distributed by: sex ( $45.8 \%$ of the participants are male, $54.2 \%$ female); population density in Northern Italy; and voluntary organizations located in Lombardy and Emilia Romagna. ${ }^{1}$ Some $31.3 \%$ of them declared to be students, $42.4 \%$ workers, and $36.3 \%$ working students or searching for a job. In this study, by "volunteer" we specifically mean a person who is involved in voluntary organizations working with minors, for a minimum of three hours a week or at least 20 days a year.

\section{Instruments}

Referring to Omoto and Snyder's work (1995) and to Clary and colleagues research (1998), volunteers completed measures of motivation to volunteer, prosocial personality, satisfaction with the organization, integration with the organization, and intention to volunteer in the next 3 and 5 years. Below follows a brief description of each measure.

\footnotetext{
1 These are two large areas in the north of Italy, historically considered the "cradle" of Italian volunteerism (Italian Welfare Ministry, 2000).
} 
To assess motivation to volunteer, we used Omoto and Snyder's Voluntary Function Inventory (VFI) (Clary et al., 1998). This scale well represents all the kinds of motivation that can be spurred by a volunteer when actively engaged. The original scale, comprising 30 items, measures motivations for volunteering by analyzing six functions-values, career, social, knowledge, ego-protective, and self-enhancement-with a 5-step Likert scale response set (from "Not at all" to "Very much"). This is a revised version of a previous scale adopted in Omoto \& Snyder's, 1995 research projects. In this latter version the community concern motivation is associated to the value motivation. The construct validity of the VFI scale has been examined using factor analysis. An oblimin factor analysis on the scores of the 461 young Italian volunteers led to the identification of four factors explaining in total $62.6 \%$ of variance.

The first factor, comprising 5 items, explained $25.5 \%$ of variance: it represents "social motivation," that is, responding to the need for affiliation and social adaptation. An example of an item in this factor is: "The people I know share an interest in community service." The scale's reliability, measured with Cronbach's Alpha, was .80. The second factor also comprises 5 items (16.7\% of the total variance). It represents "career motivation," the opportunity to acquire or reinforce skills and competencies related to a future professional or working activity $(\alpha=.85)$. An example of an item is: "Volunteering will help me succeed in the profession I choose." The third factor, comprising 3 items (10.4\% of the total variance), represents "ego-protective motivation," that is, the wish to defend oneself from negative feelings $(\alpha=.71)$. An example of an item is: "In times of trouble or suffering, volunteering helps me keep my mind off my problems." Finally, the fourth factor, also comprising 3 items, represents the "values motivation" referring to the opportunity to concretely express one's values (9.2\% of the variance, $\alpha=.66)$. An example of an item is: "By volunteering I can contribute to a cause that I deem important."

To assess prosocial personality, which according to our theoretical framework is one of the predictor of long-term volunteerism (Omoto \& Snyder, 1995), Caprara, Pastorelli, and Bandura's Prosocial Personality Scale, $(1992,1996)$ was used. This Italian scale comprises 21 items measuring the propensity of subjects towards helping behavior, collaboration, promotion of initiatives benefiting others, and sharing. It is a single-factor scale, with a total explained variance of $32.6 \%$ and a Cronbach's Alpha of .90. An example of an item is: "I quickly come to the aid of someone who is in need."

In order to assess satisfaction and integration with the organization, we developed two ad hoc instruments. Namely:

Satisfaction with the Organization Scale permits to assess two dimensions relevant to satisfaction: "organizational satisfaction" and "activity satisfaction." The "organizational satisfaction" index measures the general satisfaction a person feels towards the volunteer organization he/she belongs to. It comprises 6 items $(\alpha=.84)$. An example of an item is: "I feel emotionally attached to this organization." The "activity satisfaction" index (6 items) measures the satisfaction one feels concerning the actual execution of one's voluntary actions $(\alpha=.75)$. An example of an item is: "I am personally very satisfied with the responsibilities I am assigned in my voluntary activities."

Integration with the Organization Index is a composite index based on one item concerning group identification and one concerning concrete participation in the group's activities. As regards to the length of service, we measured the "Intention to volunteer in the next 3 and 5 years." The intention to volunteer in the next three and five years was assessed through a single item. Recipients had to indicate their agreement on a 4-point scale ( $1=$ not at all, to $4=$ very much) with regards to their willingness to continue volunteering. 


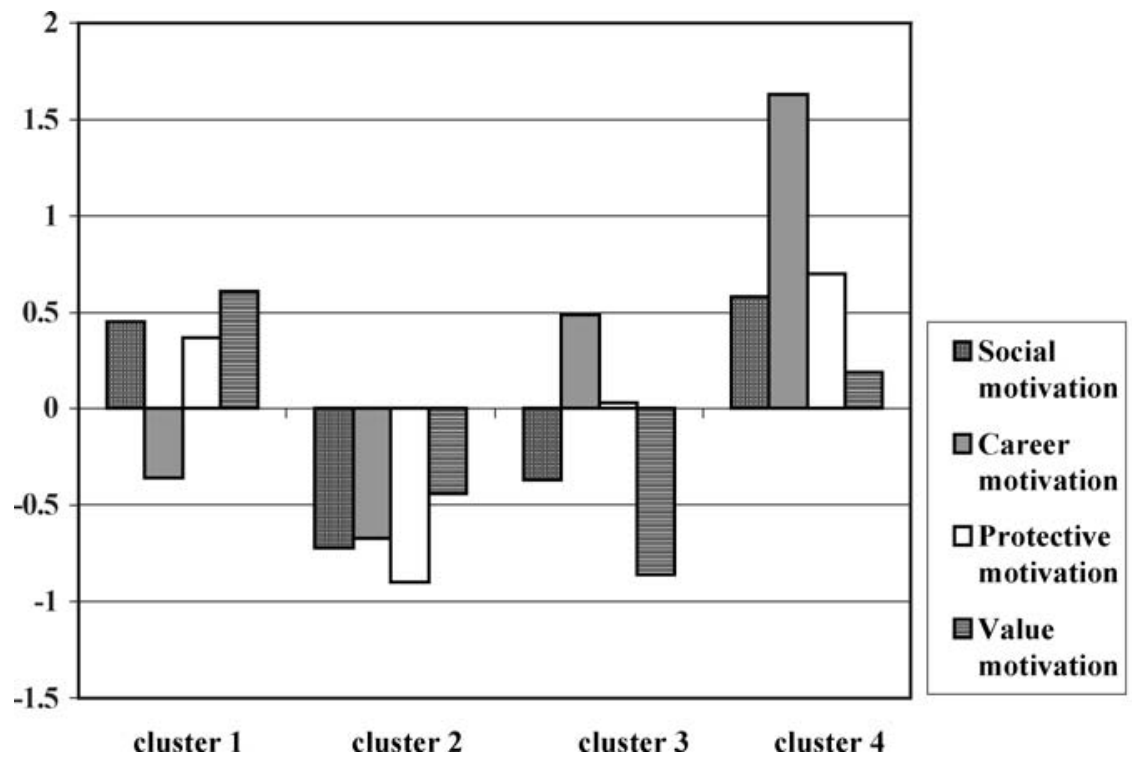

Fig. 1 Clusters of young-adult motivations ( $z$-scores)

Participants also answered some demographic questions and some items attesting to their access and length of service (duration) and their weekly commitment (in terms of hours).

\section{Analysis and results}

In relation to the objectives of the study we performed a hierarchical cluster analysis, an exploratory procedure that identifies subgroups of individuals who share similar patterns of scores on a set of variables, using Ward's aggregation method on the four motivations in order to discover in which combinations they occurred (see Fig. 1). Moreover, a series of ANOVA one-way and chi squared analyses were performed to ascertain the connotation of each subgroup in relation to variables, which were deemed of high significance to the process of voluntary commitment.

Through the cluster analyses performed on the four motivational scores (social, values, career, and ego-protection), four clusters emerged (see Table 1 for detailed mean $z$-scores):

Table 1 One-way analysis among the 4 clusters (both A clusters significantly differ from B, on each variable)

\begin{tabular}{llllll}
\hline $\begin{array}{l}\text { Variables } \\
\text { Prosocial behavior }\end{array}$ & $F(3.435)=13.61 ; p=.001$ & $\begin{array}{l}\text { Cluster 1 } \\
\text { (post-hoc) }\end{array}$ & $\begin{array}{l}\text { Cluster 2 } \\
\text { (post-hoc) }\end{array}$ & $\begin{array}{l}\text { Cluster 3 } \\
\text { (post-hoc) }\end{array}$ & $\begin{array}{l}\text { Cluster 4 } \\
\text { (post-hoc) }\end{array}$ \\
$\begin{array}{l}\text { Organizational } \\
\quad \text { satisfaction }\end{array}$ & $F(3,455)=20.16 ; p=.001$ & $.31(.87) \mathrm{A}$ & $-.28(.97) \mathrm{B}$ & $-.38(1.2) \mathrm{B}$ & $.37(.87) \mathrm{A}$ \\
$\begin{array}{l}\text { Integration } \\
\text { Activity satisfaction }\end{array}$ & $F(3,0) \mathrm{B}$ & $-.34(.99) \mathrm{B}$ & $.32(.86) \mathrm{A}$ \\
& $F(3,455) 13.65 p=.001$ & $.29(.90) \mathrm{A}$ & $-.25(1.0) \mathrm{B}$ & $-.40(1.0) \mathrm{B}$ & $.17(.88) \mathrm{A}$ \\
\hline
\end{tabular}


Cluster 1 groups $39.3 \%$ of the cases and is taken to represent "values-oriented volunteers with a social interest:" in this group the subjects have higher than average scores in terms of social, protective, and values-oriented motivations, while they have lower than average scores in terms of career motivation. These subjects have a very high values-oriented motivation, but they also seem to be driven to volunteer by a social interest, only moderately by a personal interest of self-protection, and in no measure by career-related utilitarian motivations.

Cluster 2 groups $28.7 \%$ of the cases and represents "volunteers by chance." They have lower than average scores in all the motivations investigated through the instrument. They seem to volunteer mainly in order to fill their time.

Cluster 3, grouping $16.5 \%$ of the cases, is represents "career-oriented volunteers." It comprises young people who volunteer exclusively for utilitarian reasons, i.e., to acquire new skills and knowledge that can be used towards their future professional development. As shown in Table 1, the protective motivation factor score is equal to the sample's average. The career motivation is higher than the sample average, while the scores related to social motivations and especially the ones related to values-oriented motivations are lower. This cluster has the lowest factor scores in terms of values-oriented motivations.

Finally, Cluster 4, grouping $15.5 \%$ of the cases, is represents "opportunistic volunteers with a social interest." These young people seem to volunteer for career-related, utilitarian, and self-protective reasons, but they also score well to higher than average in terms of social and values-oriented motivations. This cluster has the highest factor scores in terms of career-oriented motivations.

In response to the second research question posed above and in order to better describe the four clusters, a series of one-way ANOVA's with the cluster typology as independent variable was carried out; pro-social personality, satisfaction with the activity, satisfaction with the organization, and integration into the organization as dependent variables.

The one-way analyses and the Scheffè post-hoc test revealed the presence of statistically significant differences (see Table 1) between clusters 1-4 and clusters 2-3 in terms of the following variables: pro-social behavior, satisfaction with the organization in which the subjects were involved, integration, and satisfaction with the volunteering activity carried out. Specifically, for all these variables the volunteers in clusters 1 and 4 obtained higher scores than those in clusters 2 and 3, while there were no significant differences between clusters 1 and 4 and between clusters 2 and 3. With regard to our third objective, we performed a chi-square analysis on the socio-demographic variables of sex, age, and occupation, and on the variables related to the volunteering activity: access, duration, weekly commitment, and intention to volunteer in 3 and 5 years.

The analysis revealed no significant differences between the four clusters in relation to sex and age. In terms of occupation, however, as shown in Fig. 2, cluster 1 had the highest percentage of university students, cluster 2 had the highest percentage of workers, and clusters 3 and 4 had the highest percentage of people looking for a job.

With respect to the duration of the volunteering activity (i.e., how long the volunteering had been going on) and to the weekly commitment (measured in hours per week), no differences emerged between the four clusters. As to the intention of continuing to carry out a volunteer activity in the near future, the subjects of the first and fourth clusters assert, in percentages notably higher than those of the subjects in the second and third clusters, that it is very or quite probable that they will still be volunteering in three $\left(\chi^{2}(3)=13,78 ; p=.004\right)$ and five years $\left(\chi^{2}(3)=10,22 ; p=.02\right)$, even if with the passage of time the differences between the groups diminish slightly. 


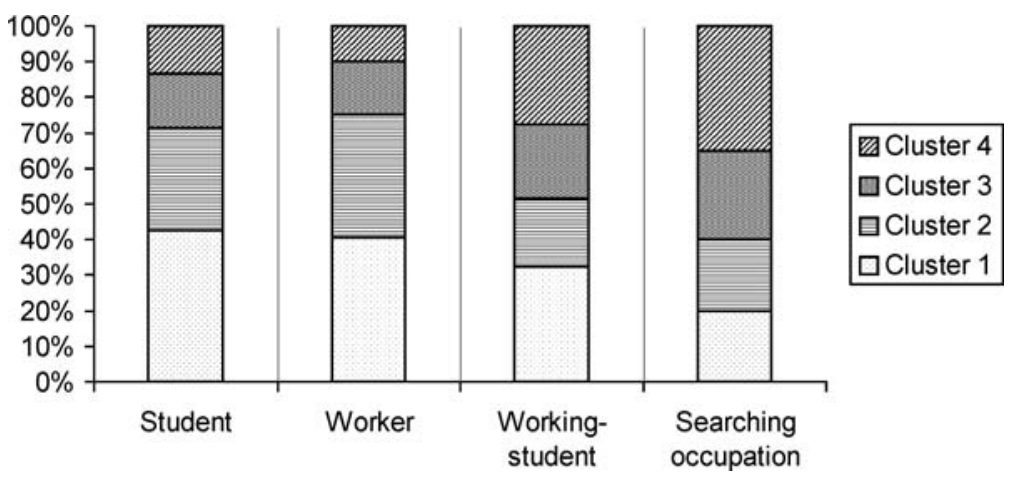

Fig. 2 Young-adult volunteers distribution according to the occupation among the 4 clusters

\section{Discussion and conclusion}

The present study was designed to explore the motivations behind young people's voluntary actions by considering how different motivations can combine into a coherent pattern and how these are associated with other crucial volunteerism variables.

In the first place, the findings tell us that the motivational configuration present in young people is varied and internally highly differentiated: young people do not all act on the basis either of same motivations or, most importantly, of the same combination of motivations. In the second place, if we look at the motivational pattern of young volunteers, the present study reaches conclusions that appear to question the hypothesis put forward by Kiviniemi and colleagues (2002), in whose opinion a multiplicity of motivations gives rise to dissatisfaction with the voluntary activity and inhibits commitment to it, while a single motivation creates satisfaction and promotes commitment.

According to our findings, young adults with a very composite motivational framework (clusters 1 and 4) seemed to be more satisfied on different levels (organization and activity itself), more integrated into the organization, and more willing to remain active in volunteering for a longer duration of time. The presence in the same person of different and opposite motivations (instrumental vs. values) seems to have a positive enhancing effect on voluntary action. As stated by Bramanti (1989), social involvement can develop and consolidate only when the needs of both parties_-volunteer and recipient—are jointly considered. On the other hand, young adults in cluster 3, who are very clearly motivated only by career concerns and perspectives, manifest a sort of "temporary commitment" to the activity and the organization. The choice to become a volunteer is very closely related to professional self-improvement and no other motivation can sustain the choice to volunteer after the young person has found a good job, at least for the time being.

There are several reasons to conduct a more in-depth investigation into the unusual motivational or, better, non-motivational pattern exhibited by cluster 2 . In this cluster we find mainly workers, who are not particularly pro-social, are dissatisfied with the voluntary activity and with the organization they belong to, and are not very committed to continuing their involvement, even though they may have been carrying it out for a long time and for many hours a week. They seem to be volunteering to "fill time" or to passively maintain a commitment made in the past. Or perhaps these are individuals spurred to action by "degenerate intentions" (Kuhl, 1983) that prevent them from freeing themselves from actions decided in the past (even though no longer satisfactory), and from creating other plans for 
action. Only further investigation, especially in the form of qualitative surveys, will be able to explain why some young adults continue an activity at high personal cost without any motivation, any satisfaction, and any pro-social impetus.

The study of motivation has many organizational implications especially for those who manage volunteer organizations. In a very interesting study about volunteer motivations, Omoto and Snyder (1993) argue that organizations that are highly dependent on volunteer labor should systematically assess volunteers' motivations and then target recruitment, placement, and retention efforts on the basis of particular sets of motivations. In this way, organizations can more efficiently recruit new volunteers by identifying their true motivations. In addition, in order to promote the organization's activity, volunteers should be assigned to activities that are consistent with their underlying motivations and should be supported in recognizing the ways in which the activity in which they are involved is linked to their psychological motivations and needs. Volunteers would thus be more satisfied with their work and could achieve better results for themselves and for the organizations.

Therefore, it might also be necessary to periodically reassess volunteers' motivations, for example, through an annual survey that includes some questions about motivations for continuing volunteer service, in order to plan any changes in their activity. Motivations may indeed change and evolve during a person's voluntary service. One of the most critical problems facing volunteering-based organizations is the high level of turnover, which places a high cost on volunteer organizations in terms of staff time needed to train and orient new recruits. Even if this is inevitable in some respects, this study suggests that turnover might be reduced by taking into account the initial and ongoing motivations of volunteers.

Assessing the motivational pattern that guides young people is thus extremely important to understanding the phenomenon of volunteering during the transition to adulthood. This phenomenon is of the greatest relevance to the development of community and civic society because being engaged in the community early in life is found to be of utmost importance in developing responsible and civically active adults (Oesterle et al., 2004; Youniss and Yates, 1997).

\section{References}

Allen, N., \& Rushton, J. P. (1983). Personality characteristic of community health mental health volunteers: A review. Journal of Voluntary Action Research, 12, 36-49.

Benson, P. (1993). The troubled journey: A portrait of 6-12 Grade Youth. Minneapolis: Search Institute.

Bramanti, D. (1989). Soggettività e senso nell'agire volontario (Subjectivity and sense in voluntary acting). In: V. Cesareo \& G. Rossi (Eds.), L'azione volontaria nel mezzogiorno tra tradizione e innovazione (pp. 23-45). Bologna: Edizioni Dehotoniane.

Capanna, C., Steca, P., \& Imbimbo, A. (2002). Una scala per la misura della motivazione al volontariato (A scale to misure the motivations of volunteers). Rassegna di Psicologia, 19(1), 73-90.

Caprara, G. V., Pastorelli, C., \& Bandura, A. (1996). La misura del disimpegno morale in età evolutiva (The measure of the moral disengagement in evolutionary age). Età Evolutiva, 51, 18-29.

Chacon, F. F., \& Vecina, J. M. (2000). Motivation and burnout in volunteerism. Psychology in Spain, 4(1), 75-81.

Clary, E. G., Snyder, M., Ridge, R. D., Copeland, J., Stukas, A. A., Haugen, J., \& Miene, P. (1998). Understanding and assessing the motivation of volunteers: A functional approach. Journal of Personality and Social Psychology, 74, 1516-1530.

Deaux, K., \& Stark, B. E. (1996). Identity and motive: An integrated theory of volunteerism. Paper presented at the annual meeting of the Society for the Psychological Study of Social Issues, Ann Arbor, MI.

Flanagan, C., Bowes, J., Jonsonn, B., Csapo, B., \& Sheblanova, E. (1998). Ties that bind: Correlates of adolescents' civic commitment in seven countries. Journal of Social Issues, 54, 457-476.

Fletcher, A. C., Elder, G. H., \& Mekos, D. (2000). Parental influences on adolescent involvement in community activities. Journal of Research on Adolescence, 10(1), 29-48. 
Frisch, M. B., \& Gerrard, M. (1981). Natural helping system: A survey of Red Cross volunteers. American Journal of Community Psychology, 9, 567-579.

Gidron, B. (1977). Volunteer work and its rewards. Volunteer Administration, 11, 18-32.

Grube, J. A., \& Piliavin, J. A. (2000). Role identity, organizational experiences, and volunteer performance. Personality and Social Psychology Bulletin, 26(9), 1108-1119.

Guglielmetti, C., \& Marta, E. (2003). La matrice familiare dell'impegno dei giovani volontari: uno studio esplorativo (The familiar matrix of young volunteers engagement: an exploratory study). In E. Marta \& E. Scabini (Eds.), Giovani volontari. Firenze: Giunti.

Hanks, M. (1981). Youth, voluntary association and political socialization. Social Forces, 60, 211-233.

Hart, D., \& Fegley, S. (1995). Altruism and caring in adolescence: Relation to self understanding and social development. Child Development, 66, 1347-1359.

Hoffman, M. L. (1976). Empathy, role taking, guilt and development of altruistic motives. In T. Lickona (Ed.), Moral development and behavior: Theory, research, and social issues. New York: Holt, Rinehart and Winston.

Jenner, J. R. (1982). Participation, leadership, and the role of volunteerism among selected women volunteers. Journal of Voluntary Action Research, 11, 27-38.

Kaplan, M. (1997). The benefits of intergenerational community service projects: Implication for promoting intergenerational unity, community activism, and cultural continuity. Journal of Gerontological Social Work, 28, 211-228.

Katz, D. (1960). The functional approach to the study of attitudes. Public Opinion Quarterly, 24, 163-204.

Keniston, K. (1971). Youth and dissent: The rise of a new opposition. New York: Harcourt Brace Jovanovich.

King, M., Walder, L., \& Pavey, S. (1970). Personality changes as a function of volunteer experience in a psychiatric hospital. Journal of Consulting and Clinical Psychology, 35, 423-425.

Kirkpatrick Johnson, M., Beebe, T., Mortimer, J. T., \& Snyder, M. (1998). Volunteerism in adolescence: A process perspective. Journal of Research on Adolescence, 8, 309-332.

Kiviniemi, M. T., Snyder, M., \& Omoto, A. M. (2002). Too many of a good thing? The effects of multiple motivation on stress, cost, fulfilment and satisfaction. Personality and Social Psychology Bulletin, 28, 732-743.

Kuhl, J. (1983). Motivation, konflikt and handlungskontrolle. Berlin: Springer.

Oesterle, S., Kirkpatrick Johnson, M., \& Mortimer, J. T. (2004). Volunteerism during the transition to adulthood: A life course perspective. Social Forces, 82(3), 1123-1149.

Okun, M. (1994). The relation between motives for organizational volunteering and frequency of volunteering by elderly. Journal of Applied Gerontology, 13, 115-126.

Okun, M. A., \& Schultz, A. (2003). Age and motive for volunteerism: Testing hypotheses derived from socioemotional selectivity theory. Psychology and Aging, 18(2), 231-139.

Omoto, A. M., \& Snyder, M. (1993). Aids volunteers and their motivations: Theoretical issues and practical concerns. Nonprofit Management and Leadership, 4, 156-176.

Omoto, A. M., \& Snyder, M. (1995). Sustained helping without obligation: Motivation, longevity of service, and perceived attitude change among Aids volunteers. Journal of Personality and Social Psychology, 68, $671-686$.

Omoto, A. M., Snyder, M., \& Berghuis, J. P. (1993). The psychology of volunteerism: A conceptual analysis and a program of action research. In: B. Pryor, \& G. D. Reeder (Eds.), The social psychology of HIV infection. Hillsdale: Lawrence Erlbaum.

Omoto, A. M., Snyder, M., \& Martino, S. (2000). Volunteerism and the life course: Investigating age-related agendas for action. Basic and Applied Social Psychology, 22, 181-197.

Pancer, S. M., Pratt, M. W., \& Hunsberger, B. (1998). Community and political involvement in adolescence. What distinguishes the activist from the uninvolved? Paper presented at the 7th Biennial Meeting of the Society for Research in Adolescence, San Diego.

Penner, L. A. (2002). Dispositional and organizational influences on sustained volunteerism: An interactionist perspective. Tampa: University of South Florida Press.

Penner, L. A., \& Finkelstein, M. A. (1998). Dispositional and structural determinants of volunteerism. Journal of Personality and Social Psychology, 74(2), 525-537.

Piliavin, J. A. (forthcoming). Planned and long-term helping. In J. Dovidio, J. A. Piliavin, L. Penner, \& D. Schroeder (Eds.), The social psychology of prosocial behavior. Hillsdale: Lawrence Erlbaum.

Pozzi, M., \& Marta, E. (2006). Determinanti psico-sociali del volontariato durante la transizione all'età adulta (Psycho-social determinants of volunteerism during the transition to the adult age). Psicologia Sociale, 1, 175-196.

Smith, M., Bruner, J., \& White, R. (1956). Opinions and personality. New York: Wiley.

Snyder, M., \& Omoto, A. M. (2000). Doing good for self and society: Volunteerism and the psychology of citizen participation. In M. Van Vougt, M. Snyder, A. Tyber, \& A. Biel (Eds.), Cooperation in modern society. New York: Routledge. 
Sundeen, R., \& Raskoff, S. (1994). Volunteering among teenagers in the United States. Nonprofit and Voluntary Sector Quarterly, 23, 383-403.

Wilson, J. (2000). Volunteering. Annual Review of Sociology, 26, 215-240.

Wuthnow, R. (1995). Learning to care. New York: Oxford University Press.

Yates, M., \& Youniss, J. (1996). Community service and political moral identity in adolescents. Journal of Research on Adolescence, 6, 271-284.

Youniss, J., \& Yates, M. (1997). Community service and social responsibility in youth. Chicago: University of Chicago Press. 